\title{
As marcas de cor/raça no ensino médio e seus efeitos na educação superior brasileira
}

\author{
Amélia Artes ${ }^{1}$ \\ ORCID: 0000-0001-7296-9820 \\ Sandra Unbehaum ${ }^{1}$ \\ ORCID: 0000-0003-0602-4583
}

\section{Resumo}

Nas últimas décadas, observa-se um crescimento da participação de estudantes negros no ensino superior no Brasil, apontando uma mudança no perfil étnico-racial. Esse novo cenário é resultado da pressão dos movimentos sociais negros com a conquista de diferentes políticas de inclusão por meio de cotas, iniciadas nos anos de 1990 e fortalecidas nos anos 2000. Apesar das iniciativas, a participação de negros em comparação com o total da população é ainda distante da desejada. Para compreender essa realidade, é necessário trazer à discussão informações quantitativas para caracterização do percurso dos jovens no ensino médio e das marcas das diferenciações das escolas frequentadas por brancos e negros. Para complementar as análises de pertença racial, faz-se necessário trazer outros marcadores sociais, como sexo e condição social. Trabalha-se assim com a interseccionalidade e a constituição de quatro grupos de análise: homens brancos, mulheres brancas, homens negros e mulheres negras. Como contribuição, este artigo apresenta dados disponibilizadas pelo IBGE, por meio dos Censos Demográficos de 2000 e 2010, como evidências das mudanças observadas nas instituições de ensino superior no Brasil quanto à diversidade étnico-racial. Esses dados dimensionam os desafios ainda presentes e que precisam ser enfrentados visando a uma educação de qualidade para todos.

\section{Palavras-chave}

Equidade - Acesso ao ensino superior - Ensino médio - Negros.

1- Fundação Carlos Chagas. São Paulo, SP, Brasil. Contatos: aartes@fcc.org.br; sandrau@fcc.org.br. 


\section{Marks of color/race in upper secondary education and their effects on higher education in Brazil}

\section{Abstract}

Over the past decades, there has been an increase in the participation of negros students in higher education in Brazil, which points to a change in the racial-ethnic profile. This new scenario is the result of pressure from black social movements and the achievement of different inclusion policies through quotas, initiated in the 1990s and strengthened in the 2000s. Despite such initiatives, in comparison to the total population, the participation of the negros is still far from the desired percentage. To understand this reality, it is necessary to bring quantitative information to the discussion in order to characterize the trajectory of young people in upper secondary education and the marks of the differentiation of schools attended by whites and negros. To complement the analyses of racial belonging, it is necessary to include other social markers, such as gender and social status. Therefore, we have worked on intersectionality and the constitution of four analysis groups: white men, white women, negro men, and negro women. As a contribution, this article presents data provided by IBGE, from the 2000 and 2010 Demographic Censuses, as evidence of the changes observed in higher education institutions in Brazil regarding ethnic-racial diversity. These data measure the challenges still present and that need to be overcome with a view to quality education for all.

\section{Keywords}

Equity - Access to higher education - Upper secondary education - Blacks.

\section{Introdução}

0 início do Século XXI é marcado por mudanças representativas no perfil de estudantes do ensino superior no Brasil. Observa-se desde uma ampliação do número de pessoas que acessam, frequentam e finalizam cursos de graduação e pós-graduação como uma mudança no perfil discente, tanto nos aspectos de origem social como de pertencimento étnico-racial. Um elemento também importante nessa caracterização é a possibilidade de uma análise interseccional dos marcadores de sexo e cor/raça (FRASER, 2002; CRENSHAW, 2002; MCCLINTOCK, 1995; PICITELLI, 2008).

A teoria da interseccionalidade, cunhada pela professora de direito da Universidade de Columbia, Kimberlé Crenshaw, tornou-se uma importante referência nos estudos raciais no Brasil. Para a autora, a interseccionalidade é "uma conceituação que busca capturar as consequências estruturais e dinâmicas da interação entre dois ou mais eixos de subordinação”. (CRENSHAW, 2002, p. 7). Ela aborda especificamente a forma pelo qual o racismo, o patriarcalismo, a opressão de classe e outros sistemas discriminatórios criam 
desigualdades básicas que estruturam as posições relativas de mulheres, raças, etnias, classes e outras.

Anterior à própria Crenshaw, a brasileira Lélia Gonzalez (1983) já discutia os espaços sociais ocupados pelas mulheres, em especial negras ${ }^{2}$, estabelecendo as interrelações entre os eixos de opressão; sexo, cor e classe. Ela articula duas linhagens distintas do pensamento social, o de raça e classe e o de sexo e classe. É nessa correlação analítica que Gonzalez consegue antecipar no Brasil a percepção do que viria a ser chamado, uma década depois, de abordagem interseccional. Cabe destacar que essa abordagem surge no bojo de uma reação de mulheres negras feministas e intelectuais a uma ausência sistemática da categoria raça nos estudos sobre a condição das mulheres brasileiras e nos debates e agenda política tanto do movimento feminista como no movimento negro.

Em 1985, Sueli Carneiro e Thereza Santos já denunciavam a ausência da variável cor na produção teórica, ainda que dados estatísticos a partir dos censos de 1950 a 1980 pudessem demonstrar a desigual posição socioeconômica das mulheres negras em relação às mulheres e homens brancos.

A crítica da década de oitenta mantém-se atual e desafiadora, sobretudo para pesquisadores/as brancos/as do campo dos estudos de gênero e das desigualdades e, no nosso caso, das desigualdades educacionais, cuja intersecção de raça e de gênero precisa ser considerada como uma totalidade e como elemento estruturante da compreensão das desigualdades sociais e das discriminações.

Historicamente, a discussão das desigualdades no acesso à educação tomando como recorte os marcadores de sexo e cor/raça já foi tematizada por diversos autores (ARTES, 2016; CARVALHO et al. 2009; ROSEMBERG, 2001; RICOLDI; ARTES, 2016)³. É importante ressaltar que analisar o acesso ou a conclusão de etapas de escolarização considerando os marcadores de gênero e de pertencimento racial não consiste somente em quantificar as diferenças observadas entre grupos de homens e mulheres e de brancos e negros, mas em também considerar as situações de poder/submissão presentes nas relações sociais e que, em consequência, hierarquizam as relações sociais entre homens e mulheres, entre brancos e negros. Outro aspecto, ainda que fora do escopo deste artigo, merece menção: o modo como as experiências de racismo e de sexismo são vivenciadas e significadas pelos/ as negros/as e pelas mulheres, em diferentes espaços sociais, entre os quais, a escola e as Instituições de Ensino Superior (IES).

Tratar do acesso equitativo nas diferentes etapas de escolarização remete diretamente à concepção de justiça social. Universal, atemporal e complexa, a ideia de justiça está presente no pensamento de filósofos de todos os tempos. Na contemporaneidade, recorrese, de forma pontual neste artigo, ao pensamento de John Rawls (1992) que ao associar justiça a equidade nos ajuda a refletir acerca dos desafios atuais para uma educação justa e diversa. Outra importante referência é a de Nancy Fraser, por associar ao conceito de justiça a concepção de reconhecimento (das injustiças/diferenças culturais) e a de redistribuição

2- Os autodeclarados pretos e pardos, nas pesquisas do IBGE, são considerados negros, conforme descrito por Guimarães (2002).

3- Este estudo não trabalha com a dimensão econômica (renda) em suas análises. Optando por discussões com os marcadores de sexo e cor/ raça para a discussão de renda em pesquisas domiciliares, ver Souza (2015). 
(injustiças/desigualdades socioeconômicas) como central no processo de enfrentamento das desigualdades que caracterizam, no recorte deste artigo, os percursos escolares.

Historicamente, diferentes conceitos de justiça forjam o pensamento social e filosófico sobre as relações sociais, econômicas e a vida em sociedade. Se nos Séculos XVIII e XIX, a percepção estava associada à expansão e consolidação do sistema capitalista e das repúblicas; no Século XX, a justiça passa a incluir outras dimensões, indicativas de marcadores para além dos econômicos. Para Rawls (1992), por exemplo, os princípios de justiça deveriam ser estabelecidos a partir de um acordo comum entre sujeitos em condições formais de equidade. Os princípios que aí configuram uma compreensão liberal sobre bases fundamentalmente amplas de justiça são articulados a partir da ideia de contrato social, pela qual as desigualdades reais de renda e riqueza seriam balizadas por princípios morais razoáveis. Para o autor, uma sociedade mais justa só se constituiria a partir de uma condição de igualdade de oportunidades oferecidas a todos, em condições, assim, de equidade plena. Dessa forma, as condições e a oferta de bens sociais deveriam ser repassadas preferencialmente aos menos privilegiados da sociedade, aos socialmente desfavorecidos. Nessa perspectiva, entende Rawls, que justiça e equidade significam, antes de qualquer coisa, amparar os desvalidos, corrigindo as desigualdades existentes.

Na perspectiva de Nancy Fraser (2002, 2007, 2009), o conceito de justiça tem um caráter bidimensional: a dimensão do reconhecimento do outro, do diferente ou do diverso no que concerne a valores, cultura e princípios (chamada de justiça simbólica); e na dimensão da redistribuição visando a corrigir desigualdades, que podem ser mensuradas e dimensionadas, por exemplo, por indicadores educacionais. É importante ressaltar que para Fraser essas dimensões estão interligadas no enfrentamento das injustiças. Uma concepção ampla de justiça, orientada pela norma da paridade participativa (paridade como condição de ser um par, de estar em igual condição, de estar partindo de um mesmo lugar), incluiria tanto as dimensões de redistribuição como as do reconhecimento. Superar as injustiças significaria, assim, desmantelar obstáculos institucionalizados que impedem a participação de todos em pé de igualdade.

Fraser argumenta que as soluções redistributivas da injustiça econômica e política contribuem invariavelmente para uma indiferenciação dos grupos sociais. Da mesma forma, as soluções para a injustiça de valorização cultural intensificam uma diferenciação entre os grupos sociais. Um exemplo seria pensar como o movimento feminista e os movimentos de luta contra o racismo poderiam reivindicar a redistribuição e o reconhecimento simultaneamente. 0 contexto histórico de ambos os movimentos mostra que foi necessário as mulheres negras reivindicarem veementemente um lugar de fala, uma ocupação política dos diferentes espaços políticos, inclusive no campo científico.

Ainda que existam soluções afırmativas às injustiças, que tratam de corrigir os efeitos injustos da ordem social, elas, na visão de Fraser, não alteram o sistema subjacente que os gera. $\mathrm{Na}$ contemporaneidade, as soluções afırmativas às injustiças culturais têm se associado ao multiculturalismo predominante: revalorizando as identidades de grupos desvalorizados ou não reconhecidos, ao mesmo tempo em que deixam intactas as desigualdades que os subjazem ao mesmo tempo. 
Para Fraser, a política de redistribuição afirmativa do Estado mostra-se compatível com a política de reconhecimento afirmativo do multiculturalismo predominante: ambas tendem a promover a diferenciação de grupo.

Abordar a injustiça de gênero e de raça exigiria mudar tanto a economia política como a cultura, para desfazer o círculo vicioso da subordinação econômica e cultural. Considerando o caso de uma redistribuição afırmativa combinada com o reconhecimento afırmativo, Fraser argumenta que teríamos de incluir como ação afirmativa o esforço de assegurar às mulheres, e nós acrescentamos, às mulheres negras, em uma perspectiva interseccional, uma proporção justa das oportunidades educativas, sem modificar ao mesmo tempo a natureza e o número dessas oportunidades. Assim, o reconhecimento afirmativo que combate a injustiça racial na cultura precisaria assegurar às mulheres negras o mesmo lugar e os mesmos privilégios disponíveis às mulheres brancas em suas trajetórias escolar e profissional, por exemplo.

As perspectivas de redistribuição e de reconhecimento permitem visibilizar desigualdades socioeconômicas, de gênero e de raça na estruturação de um sistema que reproduz e perpetua o sexismo e o racismo e que precisam ser enfrentados ou visibilizados para que a sociedade se torne, realmente, mais justa.

Uma mudança da redistribuição associada ao reconhecimento de grupos identitários, como o da população negra, mobilizou nos últimos anos, em especial no Brasil, uma séria de lutas propostas por diferentes movimentos sociais, mas fortemente pelo movimento negro, por políticas afırmativas no campo da educação, tendo, por exemplo, os programas de cotas para acesso e permanência em especial no ensino superior e inserção na pós-graduação.

A educação brasileira é marcada por desigualdades históricas. Boa parte dos indicadores educacionais disponíveis e de conhecimento público comprova tal afirmativa. Hasenbalg (1999) já indicava que o nível educacional da população é baixo e desigualmente distribuído e que tal realidade não deveria ser justificada apenas pelas diferentes condições econômicas dos grupos populacionais, mas deveria trazer as marcas raciais, e, acrescenta-se, as de gênero.

Um importante mecanismo para identificar as desigualdades é a utilização de indicadores sociais na área da educação. Nas últimas décadas, o incremento de novas tecnologias de informação pelas instituições públicas e privadas facilitou não apenas a coleta, mas principalmente a divulgação de informações de grupos e populações e tornou mais amigável o acesso a tais registros pelo público não especialista. No Brasil, as páginas online do Instituto Brasileiro de Geografia e Estatística (IBGE) e na área da educação, o site do Instituto Nacional de Estudos e Pesquisas Educacionais Anísio Teixeira (INEP) apresentam um farto conjunto de informações e indicadores consolidados que permitem uma avaliação da situação educacional por diferentes recortes (grupos populacionais, distribuição regional, etapas e níveis, entre muitos outros) permitindo não só a caracterização da realidade como o monitoramento das políticas públicas.

Em especial, a respeito da população negra, é importante contextualizar as mudanças provocadas pelas políticas de ação afırmativa ${ }^{4}$ consolidadas nos últimos 15

4- 0 conceito de ação afirmativa utilizado é "[...] uma ação reparadora/compensatória ou preventiva, que busca corrigir uma situação de discriminação e desigualdade infringida a certos grupos do passado, presente e futuro, durante um período limitado. A ênfase em um ou mais desses aspectos dependerá do grupo visado e do contexto histórico e social." (MOEHLECKE, 2002, p. 203). 
anos e adotadas por governos (tanto na esfera federal como estadual) e instituições de ensino privadas no Brasil. Essas medidas políticas são fruto de pressões sociais iniciadas nos anos 1990, que foram fortalecidas por meio de legislação específica, como o Estatuto da Igualdade Racial, Lei n. 12.288/10, e a Lei de Cotas, n. 12.711/12. Nas instituições privadas, o Programa Universidade para $\operatorname{Todos}^{5}$ (Prouni) e o Fundo de Financiamento Estudantil (Fies) ${ }^{6}$ privilegiam, em seus processos de ingresso, o atendimento desses grupos "historicamente minoritários" no acesso ao ensino superior.

As teorias de Rawls e Fraser, dentre outras, têm sido utilizadas para embasar as reflexões acerca das políticas de ação afirmativa e a procura por uma maior justiça (racial) nos espaços acadêmicos, com vistas ao enfrentamento das desigualdades (redistribuição) observadas na ocupação diferenciada nesses espaços de prestígio social.

Moehlecke (2004, p. 762) mostra essa aproximação:

Dialogando com as questões de sua época, seu princípio de diferença (Rawls) tem vários pontos de aproximação com as políticas de ação afirmativa, ainda que não sejam a mesma coisa. Para Rawls, as desigualdades de nascimento, os dons naturais e as posições menos favorecidas advindas de gênero, raça, etnia são imerecidas e tem que ser compensadas de algum modo.

Por outro lado, Rosemberg (2014) problematiza as discussões contemporâneas que contrapõem o direito à diferença ou à diversidade e o acesso a bens sociais com o enfrentamento às desigualdades existentes. Para a autora:

[...] é louvável que algumas políticas identitárias e também redistributivas se situem no âmbito escolar, porém, outras políticas redistributivas devem ir além da escola e apelam por atuações políticas em outras esferas e com outras estratégias. (ROSEMBERG, 2014, p. 749).

No mesmo caminho traçado por Rosemberg, este artigo pretende focar nos aspectos estruturais que marcam as desigualdades observadas nos processos educacionais, em especial no ensino superior e em sua interface com o percurso no ensino médio.

\section{Caracterização do Ensino Superior no Brasil}

Para fundamentar a análise e reflexão aqui propostas foram processadas, com o auxílio do software SPSS (Statistical Package for the Social Sciences), algumas informações disponibilizadas pelos Censos Demográficos do Instituto de Geografia e Estatística (IBGE), gerando gráficos e tabelas analisadas ao longo do texto. São apresentadas também

\footnotetext{
5- 0 Programa Universidade para Todos - Prouni tem como finalidade a concessão de bolsas de estudo integrais e parciais em cursos de graduação e sequenciais de formação específica, em instituições de ensino superior privadas. Criado pelo Governo Federal em 2004 e institucionalizado pela Lei no 11.096, em 13 de janeiro de 2005, oferece, em contrapartida, isenção de tributos àquelas instituições que aderirem ao Programa.

6- 0 Fies é um programa do Ministério da Educação destinado a financiar a graduação na educação superior de estudantes matriculados em cursos superiores não gratuitas na forma da Lei 10.260/2001. Podem recorrer ao financiamento os estudantes matriculados em cursos superiores que tenham avaliação positiva nos processos conduzidos pelo Ministério da Educação.
} 
informações, obtidas junto ao Banco Multidimensional de Estatísticas (BME) ${ }^{7}$, que permitiram a construção dos cruzamentos de sexo e cor/raça.

Um elemento importante e historicamente central nas análises das desigualdades é o contexto econômico em que diferentes grupos estão inseridos. Segundo Souza (2015), apesar de pequenas, são observadas discrepâncias entre as principais pesquisas realizadas pelo IBGE, com um sobredimensionamento dos rendimentos dos mais pobres e um subdimensionamento dos rendimentos para os mais ricos. Como o fator econômico não é central na análise que será apresentada, optou-se por trabalhar com informações do Índice de Desenvolvimento Humano organizado pelo Programa das Nações PNUD/ONU. 0 Gráfico 1 indica a ampliação de matrículas da educação superior no Brasil. Esses dados não trabalham com o recorte de cor/raça e de sexo e visam tão somente a contextualizar os marcadores sociais estudados.

Gráfico 1 - Matrículas por categoria administrativa (pública ou privada), 1960 a 2010

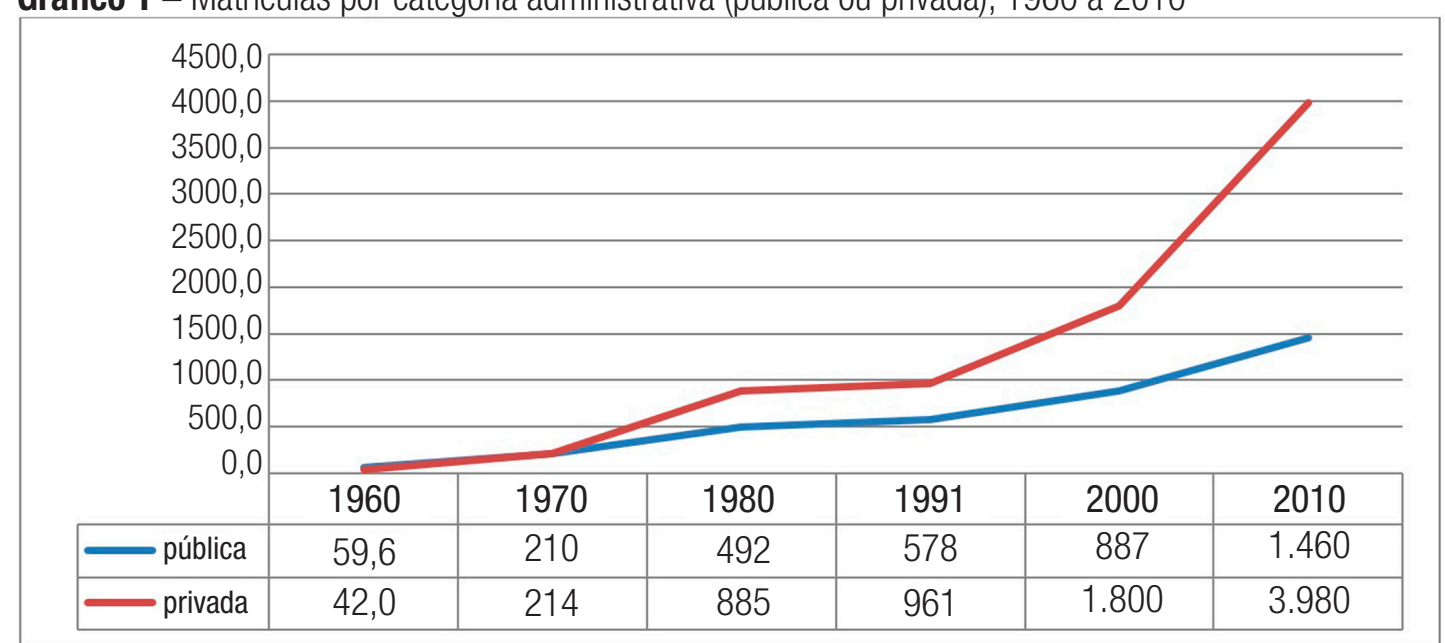

Fonte: IBGE. Dados Censo Demográfico 1960 a 2010. (elaboração dos autores)

Parte-se de quase 100 mil estudantes em 1960 para 5,4 milhões em 2010, chegando a 8 milhões em 2015/2016 ${ }^{8}$. 0 período de maior expansão ocorreu após os anos de 2000, com uma taxa de crescimento de $116,4 \%$ entre os anos de 2000 e 2010. Considerando as categorias adminstrativas, a expansão nas instituições públicas chega a 64,5\% e nas privadas a 121,1\% (NEVES; MARTINS, 2016).

\footnotetext{
7 - 0 Banco Multidimensional de Estatísticas (BME) é uma base de dados formada pelos microdados originados nas pesquisas estatísticas efetuadas pelo IBGE. Os microdados correspondem aos quesitos existentes nos questionários das pesquisas. Cada questionário vai constituir um ou mais registros de informações. Para facilitar o manuseio dos microdados são, também, acrescentadas algumas variáveis derivadas. A interface web do BME é de manuseio bastante simples, sendo capaz de resolver diversas questões para evitar uma falha de consulta, deixando o usuário escolher livremente as variáveis de seu interesse, o espaço geográfico e o período temporal de referência das informações. (https://www.bme.ibge. gov.br/apoio/produto_bme.html, acesso em 28 fev. 2020).
}

8- Informações de 2015/2016 foram coletadas no site do INEP - Censo da Educação Superior (www.inep.gov.br, acesso em 29 jul. 2019). 
A expansão nas duas modalidades deve-se às políticas desenvolvidas na Educação Básica (de ampliação das redes de atendimento no ensino médio e da regularização de fluxo no ensino fundamental, com aumento do número de potenciais alunos no ensino médio) e nos governos Luíz Inácio Lula da Silva (2003-2010) e Dilma Rousseff (2011-2016) de políticas de expansão das redes de educação superior, em especial o REUNI ${ }^{9}$ nas IES públicas e os programas de financiamento estudantil nas IES privadas.

Apesar dos avanços nos indicadores educacionais de acesso ao ensino superior, uma análise mais cuidadosa indica ainda uma distância das taxas obtidas por países com situação econômica próximas à do Brasil (OCDE, 2016).

Um importante indicador de desigualdade é a distribuição do alunado pelos marcadores de sexo e cor/raça. São, em especial, os homens negros os menos presentes nos espaços acadêmicos do ensino superior. Esse processo de exclusão inicia-se nas etapas anteriores à escolarização. Vários estudos tratam desse tema tendo como enfoque a diversidade das culturas vivenciadas na escola, revelando o racismo estrutural (GOMES, 2002, 2010; GONÇALVES, 2013). Segundo Valente (2005, p. 64), ao discorrer sobre a educação básica:

[...] o atraso escolar é menor para os brancos, e essa diferença vai se tornando mais dramática a medida que aumenta a idade do aluno; o aluno negro ou o aluno pobre é absorvido pela rede de maneira diferente do aluno de classe média ou não pobre e uma vez constituída essa clientela, os professores atuam no sentido de reforçar a crença de que os alunos pobres e negros não são mais educáveis.

Carvalho (2005, p. 88) segue no mesmo caminho trazendo para as reflexões a importância de um olhar para as diferenças nos processos cotidianos, quando considerados o sexo e a cor/ raça, como meio para compreender o pior desempenho escolar de meninos negros:

[...] a heteroclassificação de raça seria influenciada pela existência ou não de problemas escolares disciplinares ou de aprendizagem-, considerados como parte constituinte do status da criança, com uma nítida articulação entre pertencimento à raça negra, masculinidade e dificuldades na escola.

Se essas desigualdades podem ser dimensionadas no cotidiano das escolas de educação básica, por meio da observação dos espaços escolares, outro conjunto de informações estimulam estudos a partir de indicadores educacionais. Soares e Delgado (2016) apresentam medidas de mensuração das desigualdades a partir dos sistemas de avaliação, considerando, em especial, o desempenho no Saeb (Sistema de Avaliação da Educação Básica). Para os autores, os resultados aquém do desejado indicam que o direito à educação, constitucionalmente posto mesmo antes da promulgação da Constituição Federal de 1988, não é efetivamente garantido para a totalidade da população. Para os autores:

Há muitos estudantes que, embora matriculados em uma escola de ensino fundamental não aprendem o necessário para suas vidas e existem grande diferenças de aprendizados entre grupos de alunos, definidos por critérios sociodemográficos, como gênero, cor-raça, nível sócio econômico (NSE) e região de residência. (SOARES; DELGADO, 2016, p. 756).

9- Programa de Apoio a Planos de Reestruturação e Expansão das Universidades Federais (Reuni), (ver http://portal.mec.gov.br/reunisp-93318841, acesso em 13 nov. 2018). 
As desigualdades de gênero e de raça são construídas a partir de marcadores culturais de diferenciação/desvalorização desde a educação básica, podendo iniciar na própria educação infantil, conforme texto clássico de Eliane dos Santos Cavalleiro (2004). Visando a contribuir para a análise acerca das desigualdades de gênero e de raça na educação, apresentamos a seguir alguns dados sobre a participação dos jovens (demarcados pela interseccionalidade do sexo e cor/raça) no ensino superior brasileiro e a influência do ensino médio nessa trajetória escolar.

A tabela 1 indica que apenas 13,2\% da população na faixa etária de 18 a 24 anos (idade estimada para frequência no ensino superior) está matriculada em algum curso de graduação e que somente $32,1 \%$ do público atendido nessa etapa é formado por negros ${ }^{10}$, enquanto a TLM ${ }^{11}$ para os brancos é mais do que o dobro da encontrada para os negros. Essa situação tem sido descrita por Paixão (2010); Dalfon; Feres Júnior; Campos (2013), entre outros.

Tabela 1 - Participação no ensino superior por cor/raça e TLM, Brasil, 2010

\begin{tabular}{|c|c|c|c|c|}
\hline \multirow{4}{*}{ Brasil } & Cor/raça & $\mathrm{N}$ & $\%$ & TLM \\
\hline & Branco & 2.089 .870 & 66,3 & 19,6 \\
\hline & Negro & 1.012 .110 & 32,1 & 7,8 \\
\hline & Total $^{*}$ & 3.152 .330 & 100 & 13,2 \\
\hline
\end{tabular}

Fonte: elaboração dos autores, a partir de dados do BME, IBGE, CD 2010.

Nota*: 0 total inclui os autodeclarados indígenas e amarelos. Dessa forma, a somatória branco e negro totaliza 98,4\%.

No recorte por sexo (tabela 2), as mulheres são maioria, como já descrito por Beltrão; Teixeira (2004) e Rosemberg; Madsen (2011). Nas análises a respeito da participação das mulheres no ensino superior, estudos indicam diferenças nas distribuições por sexo nos diversos cursos, com uma maior presença delas em cursos de "menor prestígio"12, em especial nas áreas da educação e da saúde e uma presença menor em cursos nas áreas das ciências exatas e tecnologias (como nas Engenharias e Ciências da Computação, entre outras).

Tabela 2 - Participação no ensino superior por sexo e TLM, Brasil, 2010

\begin{tabular}{|c|c|c|c|c|}
\hline \multirow{4}{*}{ Brasil } & Sexo & $\mathrm{N}$ & $\%$ & TLM \\
\hline & Homens & 1.353 .799 & 42,9 & 11,3 \\
\hline & Mulheres & 1.798 .542 & 57,1 & 15,0 \\
\hline & Total $^{*}$ & 3.152 .341 & 100 & 13,2 \\
\hline
\end{tabular}

Fonte: elaboração dos autores a partir de dados do BME, IBGE, CD 2010.

Nota*: A divergência de 11 sujeitos entre 0 total da tabela 1 e 2 deve-se à estimativa que gera o número total da população e que representa apenas $0,0003 \%$ da amostra, podendo ser desconsiderada nos resultados.

10- Vale lembrar que os negros totalizam mais de 50\% da população (dados no Censo Demográfico 2010 indicam 50,9\% e PNAD 2015, 53,9\%.). 11- TLM (Taxa Líquida de Matrícula): número de alunos na faixa etária oficial para determinado nível de educação matriculados nesse nível, expresso como porcentagem da população total pertencente a essa faixa etária. Relatório de Monitoramento Global Educação para Todos 2003/2004, (UNESCO, 2004, p. 287).

12- A definição de maior ou menor prestígio para cursos pode ser associada à concorrência nos vestibulares/concursos, remuneração futura da carreira ou prestígio social. 
A partir de dados dos Censos Demográficos de 2000 e 2010, a tabela 3 discrimina sexo e cor/raça gerando quatro agrupamentos: mulher branca e homem branco; mulher negra e homem negro, para apresentar a frequência na graduação, no ensino superior, mas também para demonstrar as desigualdades relacionadas a gênero e cor/raça.

Para tornar a leitura da tabela 3 mais compreensível e ao mesmo tempo provocar uma reflexão acerca de como as desigualdades se revelam, propomos um exercício hipotético de tipo ideal, como uma espécie de parâmetro. Vamos considerar que a população brasileira é composta metade por mulheres e metade por homens (dados de Censo Demográfico de 2010 indicam 51,0\% de mulheres e 49,0\% de homens) e de uma forma aproximada metade dessa população é formada por negros e a outra metade por brancos (dados de Censo Demográfico de 2010 indicam 47,5\% de brancos e 50,9\% de negros). A partir dessas aproximações definimos que cada um dos quatro grupos deveria ter idealmente uma participação no ensino superior proporcional de 25\%.

Aceitando então, como participação ideal, o percentual de 25\%, observa-se que as mulheres brancas apresentam os melhores resultados para a frequência na graduação 44,2\% em 2000 e 35,3\% em 2010, enquanto os homens negros representam respectivamente $8,2 \%$ e $14,6 \%$, com uma melhora significativa no ano de 2010, mas ainda igualmente distante do parâmetro ideal de atingir pelo menos $25 \%$.

Uma evolução no percentual de frequência na graduação de estudantes negras/os pode ser visualizada nas taxas de variação: mais do que o dobro quando comparado com as/os estudantes brancas/os (290,7\% para negras/os e 73,7\%\% para brancas/os).

Tabela 3 - Pessoas que frequentam a graduação para um conjunto de variáveis, Brasil 2000 e 2010

\begin{tabular}{|c|c|c|c|}
\hline & \multicolumn{3}{|c|}{ Frequenta a graduação } \\
\hline & 2000 & 2010 & Variação \\
\hline \multicolumn{4}{|c|}{ Sexo } \\
\hline Homem & 43,5 & 43 & 114,2 \\
\hline Mulher & 56,5 & 57 & 118 \\
\hline \multicolumn{4}{|c|}{ Cor/raça } \\
\hline Branco & 78,5 & 66 & 73,7 \\
\hline Negro & 19,5 & 36 & 290,7 \\
\hline \multicolumn{4}{|c|}{ Sexo e cor/raça } \\
\hline Mulher branca & 44,2 & 35,3 & 72,9 \\
\hline Homem branco & 34,4 & 27,7 & 74,6 \\
\hline Mulher negra & 11,3 & 20,7 & 294,9 \\
\hline Homem negro & 8,2 & 14,6 & 284,9 \\
\hline Total * & 100 & 100 & 116,4 \\
\hline
\end{tabular}

Fonte: Artes (2016), a partir de microdados do IBGE, Censo Demográfico 2000 e 2010.

Nota: *No total estão considerados os autodeclarados amarelos e indígenas. 
Adotar uma perspectiva interseccional contribui para orientar a leitura desses dados. Os estudantes não são apenas homens ou mulheres, ou brancos ou negros, amarelos e indígenas, pobres ou ricos, são simultaneamente a sobreposição de várias dessas características, que se entrelaçam e influenciam, gerando diferentes possibilidades de percursos escolares e trajetórias profissionais. Os dados apresentados na tabela 3 mostram um avanço na frequência na graduação das e dos estudantes negras e negros no percurso de uma década, mas quando comparado com a população branca, independente do sexo, é a desigualdade racial, sobretudo para os homens negros, que se destaca.

Para compreender as desigualdades observadas no ensino superior é fundamental considerar o percurso das e dos jovens negras/os a partir dos anos finais da educação básica, em especial, o ensino médio.

\section{Caracterização do ensino médio no Brasil}

Pode-se entender o ensino médio como uma etapa intermediária entre o processo escolar de apropriação e consolidação da leitura e escrita, como um espaço de formação e de preparação para o mercado de trabalho e preparatório para o ingresso no ensino superior e que tem, nas últimas décadas, recebido uma atenção especial de pesquisadores, de organizações da sociedade civil e do poder público. Essas preocupações transitam entre como entender e modificar o baixo desempenho obtido nos exames de proficiência internacionais (em especial o PISA ${ }^{13}$ ) e nacionais $\left(\right.$ ENEM $\left.^{14}\right)$ além do enfrentamento às elevadas taxas de abandono e de desinteresse ${ }^{15}$ do jovem por essa etapa de estudo.

Frente a essa realidade, programas e políticas públicas têm sido desenhadas. Em 2009, a Emenda Constitucional n. 59 ampliou a obrigatoriedade de frequência à educação básica, incluindo as etapas de educação infantil (nas idades de 4 e 5 anos) e o ensino médio (nas idades de 15 a 17 anos). Os estados, responsáveis constitucionais pela oferta de ensino médio, tinham até o ano de 2016 para universalizar o atendimento. A meta 3, definida pelo Plano Nacional de Educação 2014-2024, determina:

Universalizar, até 2016, o atendimento escolar para toda a população de 15 (quinze) a 17 (dezessete) anos e elevar, até o final do período de vigência deste PNE, a taxa líquida de matrículas no ensino médio para 85\% (oitenta e cinco por cento). (BRASIL, 2014) ${ }^{16}$.

\footnotetext{
13- 0 Program for International Student Assessment (Pisa) - Programa Internacional de Avaliação de Estudantes - é uma iniciativa de avaliação comparada, aplicada de forma amostral a estudantes matriculados a partir do $7^{\circ}$ ano do ensino fundamental na faixa etária dos 15 anos, idade em que se pressupõe o término da escolaridade básica obrigatória na maioria dos países. Disponível em: http://portal.inep.gov.br/pisa. Acesso em 29 nov. 2018.

14- Criado em 1998, o Exame Nacional do Ensino Médio (Enem) tem o objetivo de avaliar o desempenho do estudante ao fim da escolaridade básica. Podem participar do exame alunos que estão concluindo ou que já concluíram o ensino médio em anos anteriores. 0 Enem é utilizado como critério de seleção para os estudantes que pretendem concorrer a uma bolsa no Programa Universidade para Todos (ProUni). Além disso, cerca de 500 universidades já usam o resultado do exame como critério de seleção para o ingresso no ensino superior, seja complementando ou substituindo o vestibular. Disponível em: http://portal.mec.gov.br/enem-sp-2094708791. Acesso em 29 nov. 2018.

15- Ver estudo de Barros et al. (2017) que discute os fatores de desengajamento dos jovens no Ensino Médio trazendo fatores como as condições escolares como determinantes do desinteresse. Não é o jovem que se desinteressa pelos estudos, por vezes é a escola que não se apresenta como interessante aos jovens.
}

16- Meta 3 PNE. Ver http://pne.mec.gov.br/18-planos-subnacionais-de-educacao/543-plano-nacional-de-educacao-lei-n-13-005-2014. Acesso em: 19 mar. 2021. 
0 relatório de Monitoramento do Plano Nacional de Educação, publicado pelo INEP, em 2017, indica os desafios e os progressos para cumprimento dessa meta. Parte das conclusões, descritas no Quadro 1, apontam alguma melhoria nos indicadores selecionados, porém insuficiente para o alcance da meta. Explicitam ainda aspectos das desigualdades de acesso ao ensino médio, marcadas pelas diferenças regionais, por renda e étnico-racial.

Quadro 1 - Trechos selecionados das conclusões do Relatório do $2^{\circ}$ Ciclo de Monitoramento das Metas do Plano Nacional de Educação, referentes à Meta 3

1. 0 atendimento escolar da população de 15 a 17 anos de idade apresenta uma trajetória de crescimento no período analisado, chegando a 91,3\% em 2017. Não obstante, a meta de universalização do atendimento dessa população até o ano de 2016 prevista no PNE não foi alcançada.

2. 0 desafio da Meta 3 quanto à universalização do atendimento dos adolescentes de 15 a 17 anos recai sobre a evasão escolar. Cerca de 900 mil adolescentes que estão fora da escola e não concluíram o ensino médio foram matriculados no início de sua trajetória escolar na idade adequada, mas sofreram percalços nessa trajetória que os impediram de permanecer até a conclusão.

3. Há diferenças significativas na frequência à escola dos adolescentes de 15 a 17 anos segundo sua cor/raça e renda familiar. Enquanto 93,2\% dos adolescentes autodeclarados brancos frequentavam a escola em 2017 , eram $90,2 \%$ os autodeclarados negros que o faziam. Entre os $25 \%$ mais ricos, 94,9\% frequentavam ou haviam concluído a educação básica até 2015 e, entre os $25 \%$ mais pobres, apenas $80,7 \%$. As diferenças relacionadas à renda e raça não apresentaram redução no período mais recente, havendo risco de permanecerem até o fim da vigência do PNE.

4. As desigualdades regionais, de sexo, local de residência, cor/raça e renda são acentuadas no indicador de matrícula líquida ajustada, refletindo na trajetória escolar entre grupos sociais e regiões. No Nordeste, em 2017, apenas 62,7\% dos jovens de 15 a 17 anos estão no ensino médio ou já o concluíram, enquanto no Sudeste esse indicador chega a $77,7 \%$.

Fonte: Brasil (2017, p. 72).

Visando a complementar as análises referentes ao ensino médio, são apresentados os gráficos 2 e 3 com as alterações observadas entre os anos de 2012 e 2017.

Gráfico 2 - Estudantes de 15 a 17 anos que frequentavam a escola ou haviam concluído a Educação Básica (2012-2017)

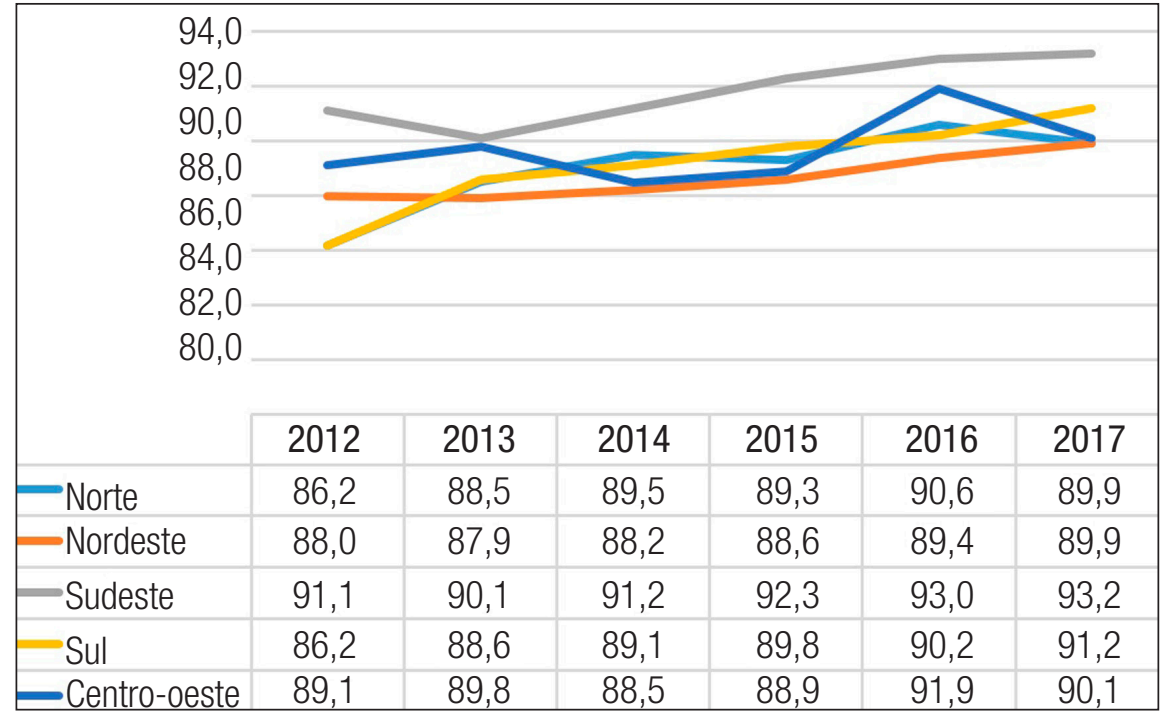

Fonte: elaboração dos autores, a partir de dados de Brasil (2017, p. 62-63). 
Em todas as regiões brasileiras houve melhora na cobertura, conforme descrição no gráfico 2 para as Taxas Brutas de Matrícula ${ }^{17}$, e que, segundo o PNE (2014-2024), deveria ter sido universalizada em 2016. Como pode ser observado, apesar da evolução na frequência, com uma melhor taxa para o Sudeste (93,3\%, em 2017), nenhuma região brasileira atingiu a meta prevista pelo PNE. A região Norte (89,9\%, em 2017) apesar de ainda distante do esperado, teve um progresso de 3,7\% de 2012 para 2017.

Gráfico 3 - Estudantes de 15 a 17 anos que frequentavam o ensino médio ou haviam concluído a Educação Básica (2012-2017)

\begin{tabular}{|c|c|c|c|c|c|c|}
\hline \multirow{9}{*}{$\begin{array}{r}90,0 \\
80,0 \\
70,0 \\
60,0 \\
50,0 \\
40,0 \\
30,0 \\
20,0 \\
10,0 \\
0,0\end{array}$} & \multicolumn{6}{|c|}{$\longrightarrow$} \\
\hline & $=$ & $=$ & 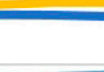 & 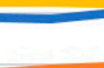 & & 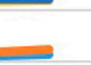 \\
\hline & \multicolumn{6}{|c|}{$\underline{ }$} \\
\hline & \\
\hline & & & & & & \\
\hline & & & & & & \\
\hline & & & & & & \\
\hline & & & & & & \\
\hline & 2012 & 2013 & 2014 & 2015 & 2016 & 2017 \\
\hline Norte & 52,2 & 55,1 & 57,7 & 58,6 & 60,5 & 61,5 \\
\hline Nordeste & 53,5 & 55,4 & 57,0 & 59,1 & 60,6 & 62,4 \\
\hline Sudeste & 72,8 & 73,5 & 75,4 & 76,2 & 78,3 & 77,7 \\
\hline Sul & 67,6 & 70,7 & 72,1 & 72,2 & 71,4 & 71,9 \\
\hline Centro-oeste & 67,9 & 69,9 & 69,6 & 68,8 & 72,2 & 72,0 \\
\hline
\end{tabular}

Fonte: Brasil, 20 Relatório de monitoramento PNE, pag. 62/63 (elaboração dos autores).

Já o gráfico 3 mostra que as Taxas Líquidas de Matrícula também estão ainda distantes da meta proposta pelo PNE, de 85\%. Os melhores resultados são apresentados pela região Sudeste $(77,7 \%)$ e os piores pelo Norte $(61,5 \%)$.

Frente a esse panorama, nos últimos anos, os percalços e desafios do ensino médio têm ocupado um espaço central nas discussões sobre a educação brasileira. Uma das principais pautas relaciona-se à melhoria dos indicadores de qualidade na educação, principalmente no comparativo com outros países do mundo.

Organizações da Sociedade Civil têm apoiado ações e programas voltados para a melhoria da gestão escolar nessa etapa, assim como ações focalizadas junto ao alunado. Suas iniciativas procuram também influenciar nas políticas educacionais por meio de ações de incidência política junto ao MEC, Secretarias Estaduais e Municipais de Educação,

17- TBM (Taxa Bruta de Matrícula): número de alunos matriculados em determinado nível de educação, independentemente da idade, expresso como porcentagem da população pertencente à faixa etária oficial relevante. 
Consed (Conselho Nacional de Secretários de Educação), Undime (União Nacional dos Dirigentes Municipais de Educação) e Conselhos de Educação, tanto no âmbito federal, estadual como municipal.

Nas universidades, o ensino médio tem ocupado um espaço cada vez maior nas pesquisas e nos debates acadêmicos. Carlos Brandão (2011) reflete sobre a EC n. 59/2009 e os desafios para o Plano Nacional de Educação, indicando que a distorção idade-série é um dos maiores entraves a serem superados. No mesmo caminho, Kuenzer (2010) mostra a estagnação nos indicadores de acesso na década de 2000 como um dos grandes desafios a ser superado para cumprimento das metas para o ensino médio propostas pelo Plano Nacional de Educação em vigor. Krawazyk (2011) apresenta um panorama do ensino médio na atualidade e discute as demandas provocadas pelo reordenamento internacional e pela empregabilidade nos tempos atuais.

Dos textos analisados para este estudo $^{18}$ não se encontraram reflexões que considerassem os marcadores sociais de sexo ou cor/raça. 0 recorte econômico, com um pior desempenho para a população pobre, é exposto por Kuenzer (2010); Frigotto (2016). Discute-se a baixa qualidade da educação ofertada no ensino médio, mas não se pergunta quem são os estudantes que fracassam? Meninos? Negros?

A tabela 4 apresenta o mesmo raciocínio hipotético de tipo ideal anterior, feito para o ensino superior, tomando como parâmetro o percentual mínimo de $25 \%$ de frequência no ensino médio para cada grupo, segundo as variáveis de sexo e cor/raça.

Tabela 4 - Pessoas que frequentam o ensino médio para um conjunto de variáveis, Brasil 2000 e 2010

\begin{tabular}{|c|c|c|c|}
\hline & \multicolumn{3}{|c|}{ Frequenta o ensino médio } \\
\hline & 2000 & 2010 & Variação \\
\hline \multicolumn{4}{|c|}{ Sexo } \\
\hline Homem & 45,2 & 46,1 & 15,4 \\
\hline Mulher & 54,8 & 53,9 & 11,5 \\
\hline \multicolumn{4}{|c|}{ Cor/raça } \\
\hline Branco & 58,5 & 46,2 & $-10,4$ \\
\hline Negro & 40,2 & 52,4 & 47,6 \\
\hline \multicolumn{4}{|c|}{ Sexo e cor/raça } \\
\hline Mulher branca & 31,7 & 24,7 & $-11,8$ \\
\hline Homem branco & 26,7 & 21,5 & $-8,7$ \\
\hline Mulher negra & 22,1 & 28,4 & 44,3 \\
\hline Homem negro & 17,9 & 24,7 & 51,7 \\
\hline Total * & 100 & 100 & 13,3 \\
\hline
\end{tabular}

Fonte: Artes (2016), a partir de microdados do IBGE, Censo Demográfico 2000 e 2010.

Nota*: No total estão considerados os autodeclarados amarelos e indígenas.

18- Bases Scielo Brasil e Google Acadêmico. 
A participação dos grupos apresenta um resultado mais próximo do parâmetro desejado (25\%) em nosso exercício. As disparidades estão entre os anos 2000 e 2010 para as mulheres brancas (saem de 31,7\% para 24,7\%) e os homens negros (de 17,9\% para 24,7\%). Isto é, os negros tiveram uma melhor taxa de acesso passando de 40,2\% de participação em 2000 para 52,4\% em 2010. 0 que pode ser compreendido como resultado na melhora do fluxo no ensino fundamental e a obrigatoriedade de frequência ao ensino médio, como já citado anteriormente. Considerando apenas os resultados de 2010, os valores destoantes do esperado $25 \%$ são para os homens brancos $(21,5 \%)$ e mulheres negras $(28,2 \%)$. Para explorar esse resultado faz-se necessário apresentar as faixas de idade frequentadas pelos jovens e não consideradas na construção da tabela: estariam as meninas negras, mesmo em idades mais tardias, frequentando o ensino médio? E os meninos brancos já teriam finalizado essa etapa? São resultados que demandam estudos específicos e que saem do escopo deste artigo.

Como a trajetória na escolarização de estudantes no ensino médio impactam seu acesso ao ensino superior, um caminho para reflexão é utilizar indicadores que mensurem a possibilidade de passagem de uma etapa para a outra de escolarização, considerando o ensino médio como condição para o acesso ao ensino superior. As informações, com base no Censo de 2010, são organizadas a partir dos quatro grupos de sexo e cor/raça: homens brancos, homens negros, mulheres brancas e mulheres negras.

Tabela 5 - Proporção de pessoas na passagem do ensino médio para o ensino superior, por sexo e cor/ raça, Brasil 2010

\begin{tabular}{|c|c|}
\hline Sexo e cor/raça & $\begin{array}{l}\text { Concluintes do ensino médio e ingressos no ensino superior* } \\
\text { (de cada } 100 \text { pessoas) }\end{array}$ \\
\hline Homem branco & $100-47$ \\
\hline Homem negro & $100-26$ \\
\hline Total homem** & $100-38$ \\
\hline Mulher branca & $100-51$ \\
\hline Mulher negra & $100-30$ \\
\hline Total mulher ${ }^{\star \star}$ & $100-41$ \\
\hline Total branca & $100-49$ \\
\hline Total negra & $100-28$ \\
\hline Total & $100-38$ \\
\hline
\end{tabular}

Fonte: Artes (2016), a partir de microdados do IBGE, Censo Demográfico 2000 e 2010.

* Proporção de pessoas de 18 a 24 anos com ensino médio concluído que cursam ensino superior. Cálculo A/A+B, sendo $A$ = Pessoas que cursam ou cursaram o ensino superior, na idade definida; $B$ = pessoas que concluíram o ensino médio, mas não cursam e nem cursaram o ensino superior, na idade definida.

** total dos grupos, incluindo os amarelos, indígenas e sem declaração de cor. 
A tabela foi organizada como um exercício de simulação para mostrar que há um público potencial, concluinte do ensino médio e apto a ingressar no ensino superior, mas parte dele não o acessa. Para isso, considera-se que os quatro grupos de sexo e cor/raça partem do mesmo patamar (hipotético) de 100 concluintes do ensino médio. Assim, se todos os grupos partissem de um mesmo patamar, 100 pessoas, tem-se que para cada 100 homens brancos que terminaram o ensino médio, 47 estão no ensino superior e de 100 homens negros somente 26 estão no ensino superior. As taxas para as mulheres brancas e negras são melhores no comparativo com os homens brancos e negros. Ou seja, o perfil daqueles que acessam o ensino superior é marcado primeiro pela cor/raça e depois pelo sexo, independente da finalização do ensino médio. Essa forma de medição das desigualdades permite dimensionar quantos jovens concluintes do ensino médio efetivamente alcançam a etapa subsequente de escolarização e compará-los com os marcadores de sexo e de cor/raça.

De forma complementar, informações pontuais obtidas no Relatório de Desenvolvimento Humano das Macrorregiões Brasileiras (2016), organizado pelo Programa das Nações Unidas para o Desenvolvimento (PNUD/IPEA), permite-nos contrapor o desenvolvimento econômico/social, dimensionadas pelo Índice de Desenvolvimento Humano ${ }^{19}$, à distribuição racial da população por regiões demográficas (Tabela 5).

Nos aspectos de desenvolvimento econômico e social, cabe destacar que as regiões Sudeste $(0,766)$, Centro-Oeste $(0.757)$ e Sul $(0,754)$ apresentam os melhores indicadores em contraposição com as regiões Norte $(0,667)$ e Nordeste $(0,633)$.

Tabela 6 - IDH por região geográfica, 2010

\begin{tabular}{c|cl}
\hline & $\vdots$ & IDH \\
\hline Norte & $\vdots$ & 0,667 \\
\hline Nordeste & $\vdots$ & 0,663 \\
\hline Sudeste & $\vdots$ & 0,766 \\
\hline Sul & $\vdots$ & 0,754 \\
\hline Centro-Oeste & $\vdots$ & 0,757 \\
\hline Brasil & $\vdots$ & 0,699 \\
\hline
\end{tabular}

Fonte: IPEA, 2016.

As regiões com menor participação de negros na população (Sul e Sudeste) apresentam o melhor IDH, com situação inversa para as regiões Norte e Nordeste, com valor próximo a 70\% de negros e pior IDHs.

19 - Medido anualmente pelo Pnud (Programa das Nações Unidas para o Desenvolvimento, órgão da Organização das Nações Unidas) o IDH vai de 0 a 1 - quanto maior o valor, mais desenvolvido deve ser considerado o país, tendo como base indicadores de saúde, educação e renda. Indicadores complexos passaram a ser desenvolvidos a partir dos anos de 1980/1990 com o objetivo de tornar operável e mensurável o bem-estar da população com vistas à formulação de políticas públicas (SANTAGADA, 1993). 
Tabela 7 - Distribuição por cor/raça e região geográfica

\begin{tabular}{|c|c|c|c|c|c|c|}
\hline & Norte & Nordeste & Sudeste & Sul & Centro-oeste & Total \\
\hline Branca & 23,2 & 29,2 & 54,9 & 78,3 & 41,5 & $47,50 \%$ \\
\hline Preta & 6,5 & 9,4 & 7,8 & 4 & 6,6 & $7,50 \%$ \\
\hline Parda & 67,2 & 59,8 & 36 & 16,7 & 19,4 & $43,40 \%$ \\
\hline Negro & 73,7 & 69,2 & 43,8 & 20,7 & 56,0 & $50,90 \%$ \\
\hline Total & 8,3 & 27,8 & 42,1 & 14,4 & 7,4 & 100 \\
\hline
\end{tabular}

Fonte: elaboração dos autores, a partir dos microdados do Censo Demográfico (IBGE, 2010).

Nota: a tabela seleciona os resultados a partir dos quesitos utilizados pelo IBGE (branca, preta e parda) acrescido da categoria negro, conforme proposto por Guimarães, 2002.

Gráfico 4 - Jovens de 19 anos que finalizaram 0 ensino médio - 2012-2017

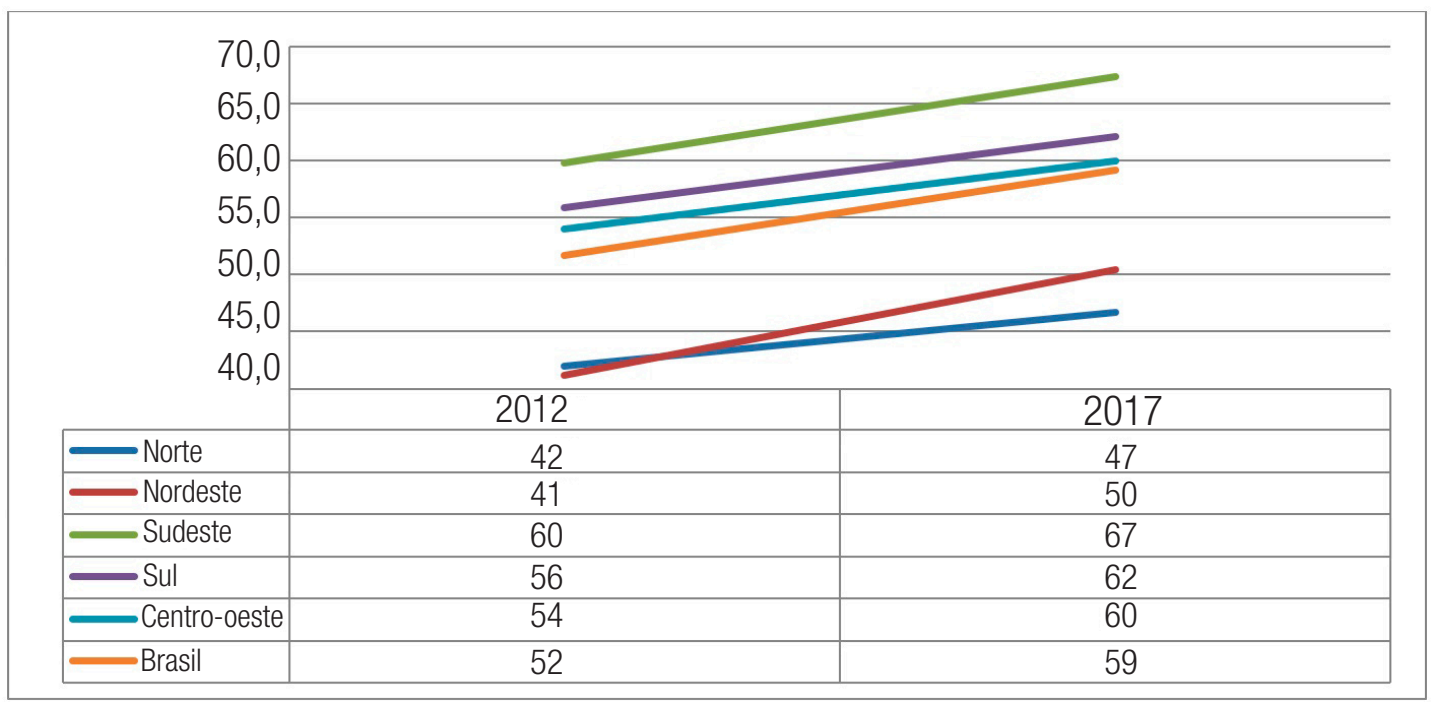

Fonte: elaboração das autoras, a partir dos dados do Todos pela Educação, Anuário Brasileiro da Educação Básica, 2018, p. 42.

De forma complementar, o gráfico 4 apresenta as taxas de finalização do ensino médio, para os anos de 2012 a 2017. É na região Norte e Nordeste que temos a menor taxa de conclusão do ensino médio (46,7\% e 50,4\%, em 2017). Dessa forma, a análise conjunta das informações de desenvolvimento humano, de pertença racial e de conclusão do ensino médio (gráfico 4) se complexifica e traz elementos importantes para pensar a interseccionalidade entre gênero, raça e condições econômicas. Uma pergunta que precisa ser feita considerando esses dados: uma menor oferta de vagas no ensino médio nas regiões Norte e Nordeste (majoritariamente de população negra) e, consequentemente, 
uma menor taxa de conclusão pode estar influenciando, numericamente, o acesso de jovens negros ao ensino superior? ${ }^{20}$

Considerando que as regiões Sudeste e Nordeste concentram a maior parcela populacional, respectivamente 42,1\% e 27,8\%, decidiu-se, por fim, comparar essas regiões em relação à possibilidade de acesso ao ensino superior a partir da finalização do ensino médio, como apresentado anteriormente para a variável sexo e cor/raça (Quadro 2).

Quadro 2 - Taxas de passagem do ensino médio para o ensino superior por sexo e cor/raça, Brasil 2010

\begin{tabular}{c:cc} 
& Proporção - Término no ensino médio por estudantes que acessam a educação \\
superior & \\
\hline Região & $\vdots$ & $100-32$ \\
\hline Sudeste & $\vdots$ & $100-41$ \\
\hline
\end{tabular}

Fonte: elaboração dos autores, a partir de microdados do Censo Demográfico 2010 - IBGE.

Nota: Proporção de pessoas de 18 a 24 anos com ensino médio concluído que cursam ensino superior. Cálculo A/A+B, sendo $A=$ Pessoas que cursam ou cursaram o ensino superior, na idade definida; $B$ = pessoas que concluíram o ensino médio, mas não cursam e nem cursaram 0 ensino superior, na idade definida.

Para cada grupo de 100 pessoas no Nordeste que finalizam o ensino médio, apenas 32 acessam o ensino superior. No Sudeste essa taxa chega a 41 pessoas. Isso indica que na região com maior participação de negros, 69,2\%, o acesso, independente das características de sexo e cor/raça é inferior ao da região Sudeste. Este dado ajuda a explicar os valores encontrados no Quadro 2 para a variável sexo e cor/raça. Isto é, a região de moradia, bem como a possibilidade de finalização do ensino médio são variáveis importantes para a compreensão das desigualdades de acesso, observadas no ensino superior e marcadas pela pertença racial do grupo.

\section{Considerações finais}

0 perfil dos estudantes que acessam o ensino superior no Brasil se alterou positivamente na última década. No aspecto de pertencimento racial, negros têm ampliado a sua presença, porém, ainda muito distante do justo considerando a sua participação na população brasileira.

O texto não explora as condições de permanência, tanto nos aspectos econômicos, como na vivência cotidiana no ambiente universitário, o qual se sabe é histórica e culturalmente constituído por valores e cultura hegemônica branca. As universidades

20- Em estudo anterior (ARTES; RICOLDI, 2015) vimos que no caso do Nordeste, apesar dos homens brancos representarem 13,8\% da população, sua presença no ensino superior é sobrerepresentada, alcançando 17,3\%; enquanto para os negros os valores são de 34,3\% na população e 21,9\% no ensino superior. Dessa forma, a questão não é apenas numérica, mas envolve dimensões outras como a do racismo estrutural. 
recebem os jovens (indicadores de acesso evidenciam), mas não necessariamente acolhem os negros, seus valores e suas culturas ${ }^{21}$.

A contribuição deste artigo é demonstrar que o processo de desigualdade de acesso de negras e negros ao ensino superior está marcado por dificuldades que esse grupo populacional encontra já nas fases anteriores de escolarização, em especial de frequentar, permanecer e concluir o ensino médio. Porém, as marcas não são apenas de cor, são os meninos, os jovens meninos, que apresentam essa trajetória mais acidentada. Dessa forma, a interseccionalidade é usada aqui como categoria descritiva de análise da realidade educacional, a partir dos dados educacionais construídos ou utilizados neste estudo. Vimos, a partir dessa perspectiva, que a realidade é particularmente mais difícil para os rapazes negros.

Os desafios para a inserção e permanência de negros no ensino superior, já descritas na literatura, mostra que os cursos por eles frequentados são, de forma geral, de baixo prestígio e concentrados nas áreas das humanidades (BELTRÃo; TEIXEIRA, 2004). Essa é uma agenda, em construção, e que precisa ser pensada nos aspectos das características de cor/raça dos grupos que ocupam os diferentes espaços de saberes. Explicitar a realidade, por si só, não resolve, mas revelar evidências é essencial para a formulação de políticas públicas eficazes e eficientes não só como reconhecimento das injustiças culturais contra a população negra, mas também no aspecto da redistribuição, considerando o acesso e a conclusão do ensino médio como critério de acesso e permanência na educação superior, como direito à educação pública de qualidade.

Este artigo, ao apresentar um conjunto de informações quantitativas para caracterizar o ensino superior brasileiro, considerando a inserção de homens e de mulheres, brancos e negros, chama atenção para a necessidade de uma melhor compreensão acerca da desigualdade racial que marca o acesso ao ensino superior. Para isso, apresenta dados de caracterização do ensino médio, condição para o acesso às etapas mais elevadas de escolarização. 0 que os dados indicam é uma desigualdade racial na conclusão do ensino médio entre brancos e negros mais intensa do que entre mulheres e homens. Porém, é com a interseccionalidade que avançamos na compreensão das desigualdades: são os homens negros que necessitam de uma atenção diferenciada se o objetivo é diminuir as desigualdades escolares existentes.

Tendo como referência o complexo debate a respeito da justiça social, cujas ideias de John Rawls e Nancy Fraser nos inspiraram, as análises dos dados indicam que tanto o reconhecimento como a redistribuição precisam ser problematizadas considerando as condições reais e objetivas de vida das e dos jovens ao longo de toda a trajetória de escolarização. Um olhar interseccional é essencial para complexificar a perspectiva sobre o acesso de jovens, homens e mulheres à educação. Os dados mostram que para uma efetiva redistribuição no campo da educação, é preciso atenção específica para a população negra, em especial, do ponto de vista de gênero, para os meninos negros, desde a sua presença (possivel ausência) na educação infantil até a pós-graduação.

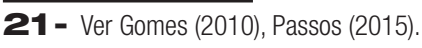


0 último Censo completa dez anos e muitas mudanças ocorreram nos processos de acesso às etapas de escolarização, como demonstrado pelos dados do relatório de monitoramento do PNE, e pelas informações da Pesquisa Nacional por Amostra de Domicílios (PNADs). É preciso confirmar essas transformações, por meio de uma nova edição do Censo, para que análises mais aprimoradas possam ser realizadas, visando a um panorama atualizado e mais fidedigno sobre as desigualdades por sexo e cor/raça nos diferentes níveis de ensino, frente às várias políticas educacionais e sociais de equidade ocorridas na última década.

\section{Referências}

ARTES, Amelia Cristina Abreu. 0 ensino médio como filtro para o acesso de negros no ensino superior brasileiro. Revista da Associação Brasileira de Pesquisadores/as Negros/as (ABPN), Uberlândia, v. 8, n. 19, p. 34-51, 2016.

ARTES, Amélia; RICOLDI, Arlene Martinez. Acesso de negros no ensino superior: 0 que mudou entre 2000 e 2010. Cadernos de Pesquisa, São Paulo, v. 45, n. 158, p. 858-881, 2015.

BARROS, Ricardo Paes de et al. Políticas públicas para a redução do abandono e evasão escolar de jovens. Brava; Instituto Unibanco; INSPER; Instituto Ayrton Senna, 2017. (Estudo).

BELTRÃO, Kaizo.; TEIXEIRA, Moema de P. 0 vermelho e o negro: raça e gênero na universidade brasileira - uma análise da seletividade das carreiras a partir dos censos demográficos de 1960 a 2000. Rio de Janeiro: IPEA, 2004. Texto para discussão.

BRANDÃO, Carlos Alberto. 0 ensino médio no contexto do Plano Nacional de Educação: 0 que ainda precisa ser feito. Cadernos Cedes, Campinas, v. 31, n. 84, p. 195-208, 2011.

BRASIL. Lei Federal 12.288, de 20 de julho de 2010. Estatuto da Igualdade Racial. Brasília, DF: [s. n.], 2010.

BRASIL. Lei Federal 12.711, de 29 de agosto de 2012. Estabelece o ingresso nas universidades federais e nas instituições federais de ensino técnico de nível médio. Brasília, DF: [s. n.], 2012.

BRASIL. Lei Federal 13.005, de 25 de junho de 2014. Aprova o Plano Nacional de Educação - PNE e dá outras providências. Brasília, DF: [s. n.], 2014.

BRASIL. Instituto Brasileiro de Geografia e Estatística. Censo demográfico. Brasília, DF: IBGE, 2000.

BRASIL. Instituto Brasileiro de Geografia e Estatística. Censo demográfico. Brasília, DF: IBGE, 2010.

BRASIL. Instituto Nacional de Estudos e Pesquisas Educacionais Anísio Teixeira. Relatório do $2^{\circ}$ ciclo de monitoramento das metas do Plano Nacional de Educação, 2017. Brasília, DF: INEP, 2017. 
CARNEIRO, Sueli; SANTOS, Thereza; COSTA, Albertina Gordo de Oliveira. Mulher negra: política governamental e a mulher. São Paulo: Nobel; Conselho Estadual da Condição Feminina; 1985. 141 p.

CAVALLEIRO, Eliane dos Santos. Do silêncio do lar ao silêncio escolar: racismo, preconceito e discriminação na educação infantil. São Paulo: Contexto, 2004.

CARVALHO, Marília. Quem é negro, quem é branco: desempenho escolar e classificação racial de alunos. Revista Brasileira de Educação, Rio de Janeiro, n. 28, p. 77-95, 2005.

CARVALHO, Marília Pinto de et al. Gênero, raça e avaliação escolar: um estudo com alfabetizadoras. Cadernos de Pesquisa, São Paulo, v. 39, n. 138, p. 837-866, 2009.

CRENSHAW, Kimberlé. Documento para o encontro de especialistas em aspectos da discriminação racial relativos ao gênero. Estudos feministas, Florianópolis, v. 10, n. 1, p. 171, 2002.

DAFLON, Verônica Toste; FERES JÚNIOR, João; CAMPOS, Luiz Augusto. Ações afirmativas raciais no ensino superior público brasileiro: um panorama analítico. Cadernos de Pesquisa, São Paulo, v. 43, n. 148, p. 302-327, 2013.

FRASER, Nancy. Mapeando a imaginação feminista: feminista: da redistribuição ao da redistribuição ao reconhecimento e à representação. Estudos Feministas, Florianópolis, v. 15, n. 2, p. 291-308, 2007.

FRASER, Nancy. 0 feminismo, o capitalismo e a astúcia da história. Mediações - Revista de Ciências Sociais, Londrina, v. 14, n. 2, p. 11-33, 2009.

FRASER, Nancy. Políticas feministas na era do reconhecimento: uma abordagem bidimensional da justiça de gênero. In: BRUSCHINI, Cristina; UNBEHAUM, Sandra Goreti (org.). Gênero, democracia e sociedade brasileira. São Paulo: Fundação Carlos Chagas; Editora 34, 2002. p. 59-78.

FRIGOTTO, Gaudêncio. Reforma do ensino médio do (des) governo de turno: decreta-se uma escola para os ricos e outra para os pobres. Movimento, Londrina, n. 5, 2016.

GOMES, Nilma Lino. Diversidade étnico-racial, inclusão e equidade na educação brasileira: desafios, políticas e práticas. Revista Brasileira de Política e Administração da Educação, Goiânia, , v. 27, n. 1, 2010.

GOMES, Nilma Lino. Educação e identidade negra. Aletria, Belo Horizonte, v. 9, p. 38-47, 2002.

GONÇALVES, Luiz Alberto de Oliveira. Reflexão sobre a particularidade cultural na educação das crianças negras. Cadernos de Pesquisa, São Paulo, n. 63, p. 27-29, 2013.

GONZALEZ, Lélia. Racismo e sexismo na cultura Brasileña. In: SILVA, Luiz Antônio. Movimentos sociais urbanos, minorias étnicas e outros estudos. Brasília, DF: Anpocs, 1983. p. 223-244.

GUIMARÃES, Antônio Sergio. Classes, raças e democracia. São Paulo, Editora 34, 2002.

HASENBALG, Carlos. Discriminação e desigualdades raciais no Brasil. Rio de Janeiro: Graal, 1999. 
INEP. Instituto Nacional de Estudos e Pesquisas Educacionais Anísio Teixeira. Sinopse estatística da educação superior 2015. Brasília, DF: INEP, 2016. Disponível em: http://portal.Inep.gov.br. Acesso em: 17 maio 2018.

IPEA. Instituto de Pesquisa Econômica Aplicada. Desenvolvimento humano nas macrorregiões brasileiras. 2016. Brasilia, DF: PNUD; IPEA; FJP, 2016.

KRAWAZYK, Nora. Reflexões sobre alguns desafios do ensino médio no Brasil. Cadernos de Pesquisa, São Paulo, v. 41, n. 144, p. 752-769, jan./abr. 2011.

KUENZER, Acácio. 0 ensino médio no Plano Nacional de Educação: 2011-2020: superando a década perdida? Educação \& Sociedade, Campinas, v. 31, n. 112, p. 851-873, jul./set. 2010.

MCCLINTOCK, Anne. Imperial leather: race, gender and sexuality in the colonial context. London: Routledge, 1995.

MOEHLECKE, Sabrina. Ação afirmativa: história e debates no Brasil. Cadernos de Pesquisa, São Paulo, n. 117, p. 197-217, 2002.

MOEHLECKE, Sabrina. Ação afirmativa no ensino superior: entre a excelência e a justiça racial. Educação \& Sociedade, Campinas, v. 25, n. 88, p. 757-776, 2004.

NEVES, Clarissa Eckert Baeta; MARTINS, Carlos Benedito. Ensino superior no brasil: uma visão abrangente. In: DWYER, Tom et al. Jovens universitários em um mundo em transformação. Brasília, DF: IPEA, 2016. p. 95-124.

OECD/UNESCO. Organization for Economic. Education at a glance 2016. Paris: OECD, 2016.

PAIXÃO, Marcelo (org.). Relatório anual das desigualdades Raciais no Brasil: 2009-2010. Rio de Janeiro: UERJ, 2010.

PASSOS, Joana Célia dos. Relações raciais, cultura acadêmica e tensionamentos após ações afirmativas. Educação em Revista, Belo Horizonte, v. 31, n. 2, p. 155-182, jun. 2015.

PISCITELLI, Adriana. Intersecionalidades, categorias de articulação e experiências de migrantes brasileiras. Sociedade e Cultura, Goiânia, v. 11, n. 2, p. 13, 2008.

RAWLS, John. Justiça como eqüidade: uma concepção política, não metafísica. Lua Nova, São Paulo, n. 25, p. 25-59, 1992.

RICOLDI, Arlene; ARTES, Amélia. Mulheres no ensino superior brasileiro: espaço garantido e novos desafios. Ex Aequo, Lisboa, n. 33, p. 149-161, 2016.

ROSEMBERG, Fúlvia. Educação formal, mulher e gênero no Brasil contemporâneo. Revista Estudos Feministas, Florianópolis, v. 9, n. 2, p. 515-540, 2001. 
ROSEMBERG, Fúlvia. Educação infantil e relações raciais: a tensão entre igualdade e diversidade. Cadernos de Pesquisa, São Paulo, v. 44, n. 153, p. 742-759, 2014.

ROSEMBERG, Fúlvia; MADSEN, Nina. Educação formal, mulheres e gênero no Brasil contemporâneo. In: BARSTED, Leila L; PITANGUY, Jacqueline. 0 progresso das mulheres no Brasil 2003-2010. Rio de Janeiro: CEPIA; Brasília, DF: ONU Mulheres, 2011. p. 390-424.

SANTAGADA, Salvatore. Indicadores sociais: contexto social e breve histórico. Indicadores Econômicos FEE, Porto Alegre, v. 20, n. 4, p. 245-255, 1993.

SOARES, José Francisco; DELGADO, Victor Maia Senna. Medida das desigualdades de aprendizado entre estudantes de ensino fundamental. Estudos em Avaliação Educacional, São Paulo, v. 27, n. 66, p. 754780, 2016.

SOUZA, Pedro Herculano Guimarães Ferreira de. A distribuição de renda nas pesquisas domiciliares brasileiras: harmonização e comparação entre Censos, PNADs e POFs. Revista Brasileira de Estudos de População, São Paulo, v. 32, n. 1, p. 165-188, Apr. 2015.

UNESCO. Relatório de monitoramento global Educação para Todos, 2003-2004. São Paulo, Organização das Nações Unidas Para a Educação, Ciência e a Cultura.

VALENTE, Ana Lúcia. Ação afirmativa, relações raciais e educação básica. Revista Brasileira de Educação, Rio de Janeiro, v. 28, p. 62-76, 2005.

Recebido em: 06.09.2019

Revisado em: 18.02.2020

Aprovado em: 09.04.2020

Amélia Artes é pesquisadora da Fundação Carlos Chagas (FCC). Doutora em educação pela Universidade de São Paulo.

Sandra Unbehaum é pesquisadora da Fundação Carlos Chagas (FCC). Doutora em educação pela Pontifícia Universidade Católica de São Paulo (PUC-SP). 